\title{
Bacteriological Investigation of Helicobacter pylori Infections in Patients with Gastric and Duodenal Ulcer
}

\author{
Haitham Refaay Mustafa Elshiekh ${ }^{1 *}$, Amr M. Elrabat ${ }^{2}$, Ahamed M. Sultan ${ }^{3}$ and \\ Mahmoud M. Zaky ${ }^{4}$ \\ ${ }^{1}$ Department of Microbiology, Faculty of Science, Al-Azhar University, Assiut, Egypt \\ ${ }^{2}$ Department of Internal Medicine, Faculty of Medicine, Mansoura University, Egypt \\ ${ }^{3}$ Department of General Surgery, Faculty of Medicine, Mansoura University, Egypt \\ ${ }^{4}$ Department of Microbiology, Faculty of Science, Port Said University, Port Said, Egypt \\ *Corresponding author
}

\section{Keywords}

H. pylori, Gastric and duodenal ulcer, Biopsy, Antibiotic sensitivity, Urease test.

\section{Article Info}

Accepted:

25 January 2017

Available Online:

10 February 2017
H. pylori colonize all human populations worldwide. The risk of being colonized by $H$. pylori depends on geographic area, socioeconomic status and age, and initial colonization is thought to occur during early childhood. In developing countries the infection can be almost ubiquitous, whereas in industrialized countries $H$. pylori infect $30-50 \%$ of adults. $H$ pylori response to both Clarithromycin and Metronidazole antibiotic sensitivity was giving the same figures. In respect to gender, $90.9 \%$ of males and $88.2 \%$ of females were sensitive to both antibiotics. Tetracycline antibiotic sensitivity was showing that $81.8 \%$ of the males and $88.2 \%$ of the females were sensitive to Tetracycline antibiotics. Amoxicillin antibiotic sensitivity was showing that, $81.8 \%$ of the males and $70.6 \%$ of the females were sensitive to Amoxicillin antibiotics. Finally Furazolidone antibiotic sensitivity was showing that, $100 \%$ of the males and $76.5 \%$ of the females were sensitive to Furazolidone antibiotics. Finally, females were more susceptible to $H$ pylori infection than male. Stool antigen analysis was more sensitive than either gram stain or urease test but still not reaching 100 percent as biopsy culture do. H pylori are more sensitive to Clarithromycin and Metronidazole while, Amoxicillin show less sensitivity in response to $H$ pylori infection. From the study we may recommend to detect $H$ pylori infection using molecular biology technique for detection of $H$ pylori gene to increase the sensitivity to $H$ pylori infection diagnosis.

\section{Introduction}

Helicobacter pylori are gram-negative spiral bacterium. Over half the world's population is infected with it, mainly during childhood, it is not certain as to how the disease is transmitted. It colonizes the gastrointestinal system, predominantly the stomach. The bacterium has specific survival conditions that the gastric microenvironment: it is both capnophilic and microaerophilic. H. pylori also exhibit a tropism for gastric epithelial lining and the gastric mucosal layer about it. Gastric colonization of this bacterium triggers a robust immune response leading to moderate to severe inflammation. This inflammatory response triggers a cascade of mucosal changes that can persist from chronic gastritis, duodenal cancer, metaplasia, dysplasia, carcinoma, to mucosal associated 
lymphoid tissue lymphoma (MALT lymphoma) (O’Connor et al., 2017).

Many individuals go through life without realizing they are infected because they were exposed young and their body sees it as normal flora. However, signs and symptoms are gastritis, burning abdominal pain, weight loss, appetite loss, bloating, burping, nausea, bloody vomit, and black tarry stools. Infection is easy enough to detect: GI X-rays, endoscopy, blood tests for anti-Helicobacter antibodies, a stool test, and a urease breath test (which is a by-product of the bacteria). If caught soon enough, it can be treated with three doses of different proton pump inhibitors as well as two antibiotics, taking about a week to cure. If not caught soon enough, surgery may be required (Goering, 2014; Wier et al., 2015).

\section{Acute infection by Helicobacter pylori}

H. pylori can survive in the superficial mucous layer by its urease activity causing a livable $\mathrm{pH}$ in its vicinity; the mechanisms by which $H$. pylori can survive and proliferate when infecting a normal stomach are not so well understood. Nevertheless, the two known voluntary infections were successful only after inhibition of gastric acidity, suggesting the role of gastric juice in the defense against the initial infection. Both these subjects developed self-limited symptoms from the epigastric area with fullness, nausea and vomiting some days after the infection and lasting for about a week (Ozbek et al., 2010).

H. pylori have retrospectively been presumed to be the causative agent. Also in these subjects, $H$. pylori may have been introduced to the stomach without gastric juice, which was continuously aspirated or as part of studying meal-stimulated acid secretion where the luminal content in vivo was titrated to $\mathrm{pH}$ 5.0. Thus, during infections, as well as the transmission by the nasogastric tube, $H$. pylori entered a stomach without acid, allowing the bacterium to bury into the mucous layer before normal gastric acidity was reestablished. In most cases of chronic $H$. pylori gastritis, there is no information of any symptomatic episode (Martínez et al., 2016).

This may indicate that most of the acute infections are asymptomatic, or alternatively, gastroenteritis due to $H$. pylori infection has been misdiagnosed as viral. Moreover, childhood $H$. pylori infection seems to be prevalent, which may be explained by reduced gastric acidity during early life Alternatively, gastroenteritis by other causes may make the gastric content hypoacidic and thus give time and possibility for $H$. pylori to proliferate and infect the stomach. The higher frequency of $H$. pylori infection in underdeveloped countries may perhaps be explained by a higher frequency of gastroenteritis in these countries. The initial infection affects both oxyntic and antral mucosa the mechanisms behind the resolution of the initial infection resulting in loss of symptoms and restoration of acid secretion Nevertheless, it seems that the infection persists in all infected subjects, with some having the ability to limit the infection to the antral mucosa whereas others develop a chronic pan-gastric infection at an early stage (Helge et al., 2016).

\section{Incidence of $\boldsymbol{H}$. pylori}

Gastric mucosa-associated lymphoid tissue (MALT) lymphoma is a rare type of nonHodgkin lymphoma (NHL) that represents $\sim 12-18 \%$ of extra-nodal NHL, with an annual incidence of 1 per 100,000 population. Nearly all patients with gastric MALT lymphoma have confirmed $H$. pylori infection, and the disease can be cured by eradicating the bacterium. H. pylori are also implicated in the majority of cases of peptic ulcer disease, 
particularly duodenal ulcer. Eradication therapy is both effective in healing peptic ulcer disease and in preventing relapse, and is cost-effective (Moleiro et al., 2016).H. pylori infection has also been associated with weight loss and failure to thrive among older adults. With respect to non-gastrointestinal diseases, clear associations between $H$. pylori and iron deficiency anaemia and idiopathic thrombocytopaenic purpura have been demonstrated, although proposed associations with a multitude of other conditions, including atherosclerotic vascular disease and neurological syndromes remain contentious (Yuan et al., 2010).

H. pylori colonize all human populations worldwide. The risk of being colonized by $H$. pylori depends on geographic area, socioeconomic status and age, and initial colonization is thought to occur during early childhood. In developing countries the infection can be almost ubiquitous, whereas in industrialized countries $H$. pylori infect 30 $50 \%$ of adults. The decline in $H$. pylori infection incidence that relates to industrialization and improvements in socioeconomic levels may be explained by the frequent use of antibiotics, improvements in sanitation, and reduced crowding. The higher prevalence of $H$. pylori in individuals over 40 years of age is considered to be due to a birth cohort effect rather than a continuous risk of being infected, i.e. the incidence of infection was higher in the past (Alberts et al., 2002).

Transmission may be related to the ability of $H$. pylori to form non-cultivable coccoid forms when exposed to unfavorable environmental conditions. However, controversy exists as to whether these coccoids are alive and important for transmission .There is also a high probability that no significant reservoirs exist outside the human stomach, since $H$. pylori has a rather small genome which does not support all necessary metabolic pathways for a nonparasitic life-style (Alm et al., 2000).

Thus, person-to person contact involving ingestion of $H$. pylori from saliva, vomits, feces or recently contaminated foods or beverages would be the most likely modes of transmission. By use of serological and DNA fingerprinting analyses, several studies have suggested that person-to-person transmission occurs mainly within families i.e. vertical transmission instead of horizontal (epidemic) transmission, which is the most common for infectious diseases (Amieva et al., 2003).

\section{$H$. pylori adhesion and invasion mechanism}

The pathogenicity of $H$. pylori and the mechanism by which it colonizes the gastricmucosa have been investigated in many studies reviewed by Huang et al., (2016). An increasing number of in vivo and in vitro studies demonstrate that $H$. pylori can invade and proliferate in epithelial cells, suggesting that this process might play an important role in disease induction, immune escape and chronic infection. Therefore, to explore the process and mechanism of adhesion and invasion of gastric mucosa epithelial cells by $H$. pylori is particularly important.

Although the detailed transmission route of $H$. pylori remains uncertain, an oral-oral or fecaloral route during childhood is thought to be the most plausible method of human-tohuman transmission (Goh et al., 2011). Once established, $H$. pylori have no significant bacterial competitors (Peek and Blaser, 2002).

The prevalence of $H$. pylori infection varies widely by geographic area, age, race, and socioeconomic status (SES), and developing appear to have higher infection rates than developed countries (Hosseini et al., 2012). 
H. pylori is unique in that the bacterium can persist for decades in the harsh stomach environment, where it damages the gastric mucosa and alters the pattern of gastric hormone release, there by affecting gastric physiology. The slow development of cancer known as Correa'scascade include a series of inter mediate stages (precancerous lesions) before malignancy per se occurs. These precancerous lesions occur in the following order: gastritis, atrophy, intestinal metaplasia (IM), and eventually dysplasia. H. pylori represent the most significant risk factor for gastric malignant tumors (Wang et al., 2014). Gastric cancer (GC) is an insidious disease, with symptoms that often manifest at an advanced stage, a time when the few remaining therapeutic options have low efficiency (Boreiri et al., 2013). Approximately $10 \%$ of infected individuals develop severe gastric lesions, such as those in peptic ulcer disease; $1-3 \%$ progress to GC, with a low 5-year survival rate, and $0-1 \%$ develop mucosa-associated lymphoid tissue (MALT) lymphoma (Parreira et al., 2013; Wang et al., 2014).

Compared with uninfected individuals, individuals infected with $H$. pylori are estimated to have a 2-8-fold increased risk of developing GC, and the International Agency for Research on Cancer (IARC) has classified $H$. pylori as a class I carcinogen. However, the inability of the immune system to clear $H$. pylori infection is not well described. Furthermore, the mechanisms controlling the induction and maintenance of $H$. pyloriinduced chronic inflammation are only partly understood (Huang et al., 2016).

A phagosome forms after $H$. pylori invades gastric epithelial cells; the bacterium then exits cells to colonize again while conditions are suitable and repeatedly infects cells. These findings suggest that invasion might play an important role in disease induction, immune escape, and chronic infection (Tan et al., 2009; Chu et al., 2010; Jang et al., 2013). In this "cellular internalization" process, a bacterium specifically binds to a host cell receptor and enters the cytoplasm via phagocytic vacuoles formed through cell membrane invagination. The pathogenic mechanism of $H$. pylori invasion and adhesion has been reviewed, (Huang et al., 2016).

\section{Aim of the work}

The work of the present study objective is to investigate the Helicobacter pylori infections bacteriological in patients with gastric ulcer in Gastroenterology center, Mansoura University.

This aim will be achieved through different aims:

1. Isolation and Identification of Helicobacter pylori from Biopsy specimen from patients with gastric and peptic ulcers.

2. Identification by rapid detection of $H$. pylori by Urease and Gimsa Stain.

3. Detect of Helicobacter pylori antigen in the stool.

4. Antibiotic sensitivity pattern and resistance.

\section{Materials and Methods}

\section{Subjects}

This study comprised fifty gastritis peptic ulcers patients, 24 of them were males and 26 were females. The mean age and standard error were $39.7 \pm 2.1$ (range: 16- 73). These patients were attending the gastroscope clinic at Gastroenterology center (GEC), Mansoura University Hospitals (MUHs), over 6 months, during the period from May 2015 to April 
2016, with symptoms and signs suggesting gastritis.

None of the examined patient had recent active gastro-inteslinal bleeding. Informed consent was obtained from each patient. All patients were subjected to:

\section{Medical examination}

Confirm the gastritis peptic ulcers using endoscopy. With biopsy specimens were taken for $H$. pylori culture.

Patients in this study were advised to stop at least 4 weeks before endoscopy

Treatment for H. pylori.

Antibiotics treatment.

Non steroidal anti-inflammatory drugs.

Antacid treatment at least 2 weeks before endoscopy.

\section{Experimental study design}

Biopsy samples were cultured in specific media for $H$. pylori growth. Positive culture were further confirmed by gram stain and urease test as well as stool antigen analysis from stool samples which taken in the same day of the biopsy.

Positive culture was also exposed to sensitivity test using different antibiotics. The antibiotics used were: Clarithromycin, Metronidazole, Tetracycline, Amoxicillin and Furazolidone.

\section{Gastric biopsy specimens}

During endoscopy using Olympus gastroscope (Q20 or Q200, Olympus, Tokyo), six antral biopsy specimens were obtained from adjacent areas of the gastric antrum with Olympus biopsy forceps FB- 24KR (Cap size, $6 \mathrm{~mm}$.). Two specimens directly dipped in 1 $\mathrm{ml}$ brain heart infusion broth in a sterile screw capped bottle for microbiological study.

\section{Media for isolation of $\boldsymbol{H}$. pylori}

Composition: Dent's medium (Cover, 2012)

a. Clumbia agar base (Oxoid).

b. Helicobacter pylori selective supplement (Oxoid).

\section{Processing of gastric biopsy specimens}

Gastric biopsy specimens in $0.5 \mathrm{ml}$ brain heart infusion broth were homogenized using tissue homogenizer (Kontes, Vineland, New Jersey) (Morgner et al., 2000). Then used for:

\section{Culture}

Two drops of homogenate were inoculated onto agar plate of Dent's medium (Selective medium) and another 2 drops were inoculated onto an agar plate of Chocolate medium (non selective medium), incubated at $37^{\circ} \mathrm{C}$ under microaerophilic conditions (Campy pale systems, BBL, Cockeysville, Maryland, USA) for up to 5 days, (Kist., 2006).

\section{Identification of isolated organism}

The growth was identified by

- Colonial Morphology

- Gram Stained Film.

- Biochemical Reaction.

- Immunological Reaction

\section{Colonial morphology}

Colonies of $H$. pylori were pin point colonies (less than $2 \mathrm{~mm}$. in diameter), gray, translucent and non hemolytic(Cover et al, 2012).

\section{Gram stained film from culture}

H. pylori are Gram negative short curved rods 
or spiral bacteria. Direct smear was prepared by vigorously rubbing the suspended specimen on a sterile glass slide with a sterile loop. After air drying the smear was fixed by heating and stained with Gram's stain, (Morgner et al, 2000).

\section{Biochemical reactions}

\section{Urease test}

Urease test was done by inoculation of a loop full of suspected organism onto Clrristensen's urea agar slant and incubated microaerophilically for 24 hours at $37^{\circ} \mathrm{C}$. Change the color from yellow to pink indicates positive urease test (Tseng et at., 2005).

\section{Immunological reaction}

Patients were asked to give a stool sample in sterile containers, which were transported to the microbiology laboratory and immediately frozen at $-20^{\circ} \mathrm{C}$ until they were tested (Ashgar, 2013).

\section{Sample preparation}

- The samples were removed from the freezer and thawed.

- Samples thoroughly mixed so that the probable antigens could locate all over the stool sample constantly.

- Stool sample approximately the size of a pea was added to $200 \mu$ of the triple buffers, i.e., $0.05 \mathrm{M}$ saline phosphate buffer, saline phosphate buffer containing $0.1 \%$ triton $\mathrm{X}-100$, and 1.5 $\mathrm{M}$ glycine buffer with $\mathrm{pH}=7.2$ which was used as a diluents.

- It was mixed thoroughly using a vortex mixer.

- Subsequently, the samples were centrifuged at $5000 \mathrm{rpm}$ for 10 minutes.
- The supernatant was transferred to a 1.5-ml Eppendorf tube that was then used for the ELISA test.

\section{Test procedures}

- For the monoclonal antibody (mAb)based Amplified IDEIA HpStAR test (Oxoid, UK).

- The supernatant of stool suspension and peroxidase conjugated mAbs were pipetted into the wells.

- After washing, substrate was added, and the results were read by spectrophotometry.

- According to manufacturer's instructions, OD values $\geq 0.190$ (450 $\mathrm{nm})$ were assessed as positive and $<0.190$ as negative.

\section{Results and Discussion}

\section{General population}

This study aimed to assess the incidence of $H$. pylori infection among gastritis with peptic ulcers patients. The patients' selection was confirmed by biopsy specimens. The work was recruited fifty gastritis peptic ulcers patients, 24 of them were males (48\%) and 26 were females (52\%) illustrated in). The mean age and standard error were $39.7 \pm 2.1$ (range: 16- 73). The frequency of $H$. pylori organism growth in selective media was $56 \%$ of all population.

Cross tabulation between gastritis patient's gender and $H$. pylori organism growth was shown in Table 1.

Within gender concept, $54.2 \%$ of the males were negative to $H$. pylori growth and 45.8 were positive. Where, $34.6 \%$ of females were negative to $H$. pylori growth and 65.4 were positive. Within organism growth concept, $59.1 \%$ of negative growth was males and 
$40.9 \%$ were females. While, $39.3 \%$ of positive growth were males and $60.7 \%$ were females.

Along the fifty patients participating in this study, $28(56 \%)$ were showing positive growth for $H$. pylori organism. Within these 28 patients, 22 were males and 17 were females.

For the positive growth patients we examine different diagnostic investigations, they were, Gram Stain (GS) and Urease Test (UT) against the golden standard test Stool Antigen Analysis (SAA). In the gold standard test Stool Antigen Analysis 4 patients were showing negative result and 24 were showing positive result. Table 2 was representing the mean age in respect to different diagnostic tool. In all diagnostic investigations the mean male age was more than the mean female age.

\section{Sensitivity and specificity of different testes} used in $\mathrm{H}$. pylori detection

The sensitivity and specificity of gram stain and Urease test against gold standard stool antigen analysis used in $H$. pylori detection was shown in (Table3). Both gram stain and urease test were show the same figure against the gold standard stool antigen analysis where both were have the sensitivity of $87.5 \%$ and specificity of $75 \%$.

When testing the sensitivity of all tests used in $H$. pylori detection against positive biopsy the sensitivity of both gram stain and urease test were $78.6 \%$ and for stool antigen analysis it was $857 \%$ (Table 4).

Table.1 Cross tabulation between gastritis patient's gender and $H$. pylori organism growth with risk estimate between males and females

\begin{tabular}{|clc|cc|c|}
\hline & & & \multicolumn{2}{|c|}{ H. pylori Growth } & P \\
& & & Negative & Positive & \\
\hline Gender & Male & Count & 13 & 11 & \multirow{2}{*}{0.134} \\
& & $\%$ within Gender & $54.2 \%$ & $45.8 \%$ & \\
& & \% within Growth & $59.1 \%$ & $39.3 \%$ & \\
\cline { 2 - 5 } & Female & Count & 9 & 17 & \\
& & \% within Gender & $34.6 \%$ & $65.4 \%$ & \\
& & \% within Growth & $40.9 \%$ & $60.7 \%$ & \\
\hline
\end{tabular}

Risk Estimate

\begin{tabular}{|l|c|c|c|}
\hline \multirow{2}{*}{} & \multirow{2}{*}{ Value } & \multicolumn{2}{|c|}{$95 \%$ Confidence Interval } \\
\cline { 3 - 4 } & Lower & Upper \\
\hline Odds Ratio for Gender (M / F) & 2.23 & 0.71 & 6.97 \\
\hline
\end{tabular}


Table.2 Mean age and standards error of the mean for participants in respect to gender and organism growth as well as different diagnostic tools

\begin{tabular}{|l|c|c|c|c|}
\hline Gender & $\mathrm{N}$ & Mean & Std. Error Mean & Significance \\
\hline Male & 11 & 38.27 & 5.54 & \\
Female & 17 & 44.05 & 3.39 & 0.35 \\
\hline G Stain & & & & \\
\hline Positive & 22 & 44.31 & 3.47 & \\
Negative & 6 & 32.50 & 4.15 & 0.04 \\
\hline Urease Test & & & & \\
\hline Positive & 22 & 43.95 & 3.54 & \\
Negative & 6 & 33.83 & 3.94 & 0.07 \\
\hline Stool Ag & & & & 0.30 \\
\hline Positive & 24 & 42.95 & 3.30 & \\
Negative & 4 & 34.75 & 6.30 & \\
\hline
\end{tabular}

Table.3 The sensitivity and specificity of gram stain and Urease test against gold standard stool antigen analysis used in $H$. pylori detection

\begin{tabular}{|l|cc|}
\hline Item & Gram Stain & Urease Test \\
\hline True Positive & 21 & 21 \\
\hline False Negative & 3 & 3 \\
\hline True Negative & 3 & 3 \\
\hline False Positive & 1 & 1 \\
\hline Sensitivity & 78.5 & 78.5 \\
\hline Specificity & 75 & 75 \\
\hline PPV & 95.9 & 95.9 \\
\hline NPV & 50 & 50 \\
\hline Accuracy & 85.7 & 85.7 \\
\hline
\end{tabular}

Table.4 The sensitivity of all tests used in $H$. pylori detection against positive biopsy

\begin{tabular}{|l|ccc|}
\hline Investigation & True Positive & False Negative & Sensitivity \\
\hline Gram Stain & 22 & 6 & 78.6 \\
Urease Test & 22 & 6 & 78.6 \\
Stool Antigen & 24 & 4 & 85.7 \\
\hline
\end{tabular}


Table.5 Cross tabulation of positive gastritis patients to H. pylori organism between clarithromycin, metronidazole, tetracycline, amoxicillin and furazolidoneantibiotic sensitivity between them

\begin{tabular}{|c|c|c|}
\hline Item & Sensitive & Resistance \\
\hline $\begin{array}{l}\text { Clarithromycin } \\
\text { Count } \\
\quad \% \text { within Clarithromycin }\end{array}$ & $\begin{array}{c}25 \\
89.2 \%\end{array}$ & $\begin{array}{c}3 \\
10.7\end{array}$ \\
\hline $\begin{array}{l}\text { Furazolidone } \\
\text { Count } \\
\quad \% \text { within Furazolidone }\end{array}$ & $\begin{array}{c}24 \\
85.7 \%\end{array}$ & $\begin{array}{c}4 \\
14.2 \%\end{array}$ \\
\hline $\begin{array}{l}\text { Tetracycline } \\
\text { Count } \\
\quad \% \text { within Tetracycline }\end{array}$ & $\begin{array}{c}24 \\
85.7 \% \\
\end{array}$ & $\begin{array}{c}4 \\
14.2 \% \\
\end{array}$ \\
\hline $\begin{array}{l}\text { Amoxicillin } \\
\text { Count } \\
\quad \% \text { within Amoxicillin }\end{array}$ & $\begin{array}{c}21 \\
75.0 \%\end{array}$ & $\begin{array}{c}7 \\
25.0 \%\end{array}$ \\
\hline $\begin{array}{l}\text { Metronidazole } \\
\text { Count } \\
\quad \% \text { within Metronidazole }\end{array}$ & $\begin{array}{c}25 \\
89.2\end{array}$ & $\begin{array}{c}3 \\
10.7\end{array}$ \\
\hline
\end{tabular}

\section{Antibiotic sensitivity to $H$. pylori growth}

Different antibiotic were used to test $H$. pylori response, they were Clarithromycin, Metronidazole, Tetracycline, Amoxicillin and Furazolidone. The sensitivity of each antibiotic was shown in table 5 .

\section{General population}

The present study paid attention to evaluate the incidence of $H$. pylori infection among gastritis with peptic ulcers patients. The patients' selection was confirmed by biopsy specimens. Since the first description of $H$. pylori by Warren and Marshall (1983), bacterium has been thought to be one of the most common human infections worldwide.

It was believed that it affected approximately half of the world's population with geographic prevalence variations (O’Connor et al., 2017).
The prevalence of $H$. pylori in the general population may be related to prevalence in symptomatic patients particularly those in whom no disease was found at endoscopy. The present work frequency of $H$. pylori organism growth in selective media was $56 \%$ of all population, this in concomitant withAdu-Aryeeet al., 2016 where theyield of H. pylori infection was $55.3 \%$.

Along different studies the prevalence of $H$. pylori was varied depending on different factors mainly the country and the site of infection where Darko et al., (2015) found a decreased among Ghanian patients over the period, $69.7 \%$ in 1999 to $45.2 \%$ in 2012 . While Obayo et al., (2015) H. pylori was diagnosed in $75.6 \%$ among the biopsied patients. Oling et al., 2015 found the prevalence of $H$. pylori gastritis was $36 \%$. In China the mean prevalence of $H$. pylori infection in the endoscopy-referral patient population was $31.97 \%$, and it mirrored a marked significant linear decline trend from 
$42.40 \%$ in 2003 to $23.82 \%$ in 2012 as reported by Jianget al., 2016.Ansari et al., 2016 found the overall prevalence of colonization of $H$. pylori was found as less as to be $16 \%$.

The present work was recruited fifty gastritis peptic ulcers patients, $(48 \%)$ of them were males and $(52 \%)$ were females. The mean age and standard error were $39.7 \pm 2.1$ (range: 16 73). Within gender concept, $45.8 \%$ of the males were positive to $H$. pylori growth while, $65.4 \%$ of the females were positive to $H$. pylori growth. Within organism growth concept, $39.3 \%$ of positive growth were males and $60.7 \%$ were females $(\mathrm{OR}=2.23$, IC $95 \%$ $=0.71-6.97 ; \mathrm{P}>0.134)$.

The present study result was in contrary with Darko et al., (2015) where their sex differences in $H$. pylori infection was identified (higher among males) and young adults (21-40 years).While in Obayo et al., (2015) study, thepatient's age were ranged from 18 to 90 years, with a mean of 53.5 years old presenting with $H$. pylori growth.

\section{Positive population for $\boldsymbol{H}$. pylori growth in media}

Along the fifty patients participating in this study, $28(56 \%)$ were showing positive growth for $H$. pylori organism. Within these 28 patients, $22(61 \%)$ were males with mean age of 38.27 years and 17 (39\%) were females with mean age of 44.05 years. In a study concerning different age ranges (Ansari et al., 2016) found that overall prevalence of colonization of $H$. pylori was found to be 16 $\%$ (male-13.3 \% and female- $20.0 \%$ ). Highest number $(36.0 \%)$ of the patients was under the age of 10 years followed by $28.0 \%$ from 11 to 20 years and $8.0 \%$ above 60 years. Out of 16 positive cases, $75.0 \%$ were below 10 years and remaining $25.0 \%$ in the age of $21-$ 40 years.
In the positive growth patients, $H$. pylori organism was identified with different diagnostic investigations, they were, Gram Stain (GS) and Urease Test (UT) against the golden standard test Stool Antigen Analysis (SAA). Where 6 (21\%) patients were showing negative GS with main age of 32.50 and 22 (79\%) were showing positive GS with main age of 44.31 . Where $6(21 \%)$ patients were showing negative UT with main age of 33.83and 22 (79\%) were showing positive UT with main age of 43.95. In the gold standard test Stool Antigen Analysis 4 (14\%) patients were showing negative result with main age of 34.75 and $24(86 \%)$ were showing positive result with main age of 42.95. In all diagnostic investigations the mean male age was more than the mean female age. The female's prevalence of positive for $H$. pylori organism is more than male.

Darko et al., (2015) demonstrate that, the relatively more females referred for upper gastrointestinal tract endoscopy compared to males. As they measure the $H$. pylori prevalence in two different time periods, there were significantly more males in the first time period (1999) compared to females, whereas females were in the majority in the second time period (2012), that the prevalence of $H$. pylori was highest among those aged between 21 and 50 years,

In the present study the diagnosis of $H$. pylori organism was confirmed with different diagnostic tests they were, Gram Stain (GS) and Urease Test (UT) against the golden standard test Stool Antigen. Detection of $H$. pylori with both gram stain and urease test were show the same figure against the gold standard stool antigen analysis where both were have the sensitivity of $87.5 \%$ and specificity of $75 \%$. When testing the sensitivity of all tests used in $H$. pylori detection against positive biopsy the sensitivity of both gram stain and urease test 
were $78.6 \%$ and for stool antigen analysis it was $857 \%$.

By screening different studies concerning the prevalence of $H$. pylori infection only one test was applied per the study beside the golden standard test of endoscopy investigation as urease test was used in many studies, (Obayo et al., 2015 \&Adu-Aryeeet al., 2016). Darko et al., (2015)use also urease test as its results are read between one minute and 24 hours (the sensitivity and specificity of these methods are in the region of $95 \%$. Jianget al., (2016) useRUT (Rapid urease test kit) for Helicobacter pylori infection status determination with a sensitivity of $99 \%$ and specificity of $100 \%$ as a single test.

$H$. pylori antigen present in stool specimen (HpSAg) was detected by immunochromatographic method using cassette (Ansari et al., 2016)withover $95 \%$ sensitivity, and $94 \%$ specificity. HpSAg is used for noninvasive and costs a fraction of what is usually charged for endoscopy. Oling et al., (2015) diagnosis of $H$. pylori infection in biopsy specimen using the Modified Giemsa stain which is easy to interpret, inexpensive, and takes about 5 min to perform, and rarely requires repeat stains. It has a sensitivity of $98 \%$ and specificity of $90 \%$.

\section{Antibiotic sensitivity to $H$. pylori growth}

In the present study different antibiotic were used to test $H$. pylori response, they were Clarithromycin, Metronidazole, Tetracycline, Amoxicillin and Furazolidone. The sensitivity of each antibiotic was calculated and statically analyzed.

H. pylori response to both Clarithromycin and Metronidazole antibiotic sensitivity was giving the same figures. In respect to gender, $90.9 \%$ of males and $88.2 \%$ of females were sensitive to both antibiotics. Tetracycline antibiotic sensitivity was showing that $81.8 \%$ of the males and $88.2 \%$ of the females were sensitive to Tetracycline antibiotics. Amoxicillin antibiotic sensitivity was showing that, $81.8 \%$ of the males and $70.6 \%$ of the females were sensitive to Amoxicillin antibiotics. Finally Furazolidone antibiotic sensitivity was showing that, $100 \%$ of the males and $76.5 \%$ of the females were sensitive to Furazolidone antibiotics.

Darko et al., (2015)given the importance of eradicating $H$. pylori infection in patients with peptic ulcer disease, it is vital that infection is treated optimally with a combination regime that has an acceptable high eradication rate in the region of $90 \%$. The incidence of $\mathrm{H}$. pylori infection in Ghana may be lower than previously reported due to changing socioeconomic factors, increased PPI and antibiotic useAdu-Aryeeet al., 2016). The burden of $H$. pylori infection among dyspeptic patients was high which decrease after antibiotic empirical treatment (Oling et al., 2015).

In conclusion, from this study we found that, females were more susceptible to $H$. pylori infection than male. Stool antigen analysis was more sensitive than either gram stain or urease test but still not reaching 100 percent as biopsy culture do. H. pylori are more sensitive to Clarithromycin and Metronidazole while, Amoxicillin show less sensitivity in response to $H$. pylori infection. From the study we may recommend to detect $H$. pylori infection using molecular biology technique for detection of $H$. pylori gene to increase the sensitivity to $H$. pylori infection diagnosis.

\section{References}

Adu-Aryee N. A., Aabakken ,Dedey F. , Nsaful J. andKudzi W. (2016): Comparison of endoscopic based diagnosis with Helicobacter urease test for 
Helicobacter pylori infection. BMC Res Notes 9:421

Alberts, B., Johnson, A., Lewis, J., Raff, M., Roberts, K. \& Walter, P. (2002): General principles of cell communication. In Molecular biology of the cell, pp. 854-856. Edited by B. Alberts, A. Johnson, J. Lewis, M. Raff, K. Roberts \& P. Walter. New York, NY: Garland Science.

Alm, R. A., Bina, J., Andrews, B. M., Doig, P., Hancock, R. E. \& Trust, T. J. (2000): Comparative genomics of Helicobacter pylori: analysis of the outer membrane protein families. Infect Immun68, 41554168

Amieva MR, El-Omar EM(2008). "Hostbacterial interactions in Helicobacter pylori infection". Gastroenterology. 134 (1): 306-23.

Ansari S, Gautam R, Nepal HP, Subedi SN, Shrestha S, Mandal F, Rimal B and Chhetri MR (2016): Helicobacter pylori colonization in Nepal; assessment of prevalence and potential risk factors in a hospital-based patient cohort. BMC Res Notes 9:59

Ashgar SS (2013):Helicobacter pylori Diagnosis by Stool Antigen ELISA and Rapid Test. Journal of Applied Medical Sciences, vol. 2, no. 4, 61-66 ISSN: 22412328 (print version), 2241-2336 (online) Scienpress Ltd,

Boreiri M., Samadi F., Etemadi A., Babaei M., Ahmadi E., Sharifi A. H., et al. (2013). Gastric cancer mortality in a high incidence area: long-term follow-up of Helicobacter pylori-related precancerous lesions in the general population. Arch. Iran. Med. 16, 343-347.

Darko R, A. E. Yawson2, V. Osei3, J. OwusuAnsah3 And S. Aluze-Ele2 Changing Patterns Of The Prevalence Of Helicobacter pylori Among Patients At A Corporate Hospital In Ghana. Ghana Medical Journal, September 2015 Volume 49, Number 3: 147- 153.

Chu, Y.T., Wang, Y.H., Wu,J.J., and Lei, H.Y.(2010). Invasion and multiplication of
Helicobacter pylori in gastric epithelial cells and implications for antibiotic resistance. Infect. Immun. 78, 41574165.doi:10.1128/IAI.00524- 10

Cover TL. Perspectives on methodology for in vitro culture of Helicobacter pylori.MethodsMol Biol.2012;921:11-15.

Goh, K.L., Chan, W.K., Shiota, S., and Yamaoka,Y.(2011).EpidemiologyofHelico bacterpyloriinfectionandpublichealthimpli cations. Helicobacter 16 (Suppl.1),19.doi:10.1111/j.1523-5378.2011.00874.x

Goering, Richard (20 May 2014). MIMS Medical Microbiology. Philadelphia: Elsevier. pp. 32, 64, 294, 133-4, 208, 303-4, 502.

Helge L. Waldum, Per M. Kleveland and Øystein F. Sørdal(2016): Helicobacter pylori and gastric acid: an intimate and reciprocal relationship. TherAdvGastroenterol , Vol. 9(6) 836844 DOI: $10.1177 / 1756283$ X16663395

Hosseini,E.,Poursina,F.,deWiele,T.V.,Safaei,H. G.,andAdibi,P.(2012). Helicobacter pylori in Iran: a system aticre view on the association of genotypes and gastroduodenal diseases. J.Res. Med.Sci. 17,280-292.

Huang Y, Wang Q-1, Cheng D-d, Xu W-t and Lu N-h (2016): Adhesion and Invasion of Gastric Mucosa Epithelial Cells by Helicobacter pylori. Front. Cell. Infect. Microbiol. 6:159. doi: 10.3389/fcimb.2016.00159

Jang,S.H., Cho,S., Lee,E.S., Kim,J.M., and Kim,H. (2013). The phenylthiophenylpropenone RK-I-123 reduces the levels of reactive oxygen species and suppresses the activation of NF-kB and AP-1 and IL-8 expression in Helicobacter pylori-infected gastric epithelial AG Scells. Inflamm.Res. 62, 689-696.

Jiang JX, Qing Liu2†, Xin-Yi Mao3, Hai-Han Zhang1, Guo-Xin Zhang1 and Shun-Fu $\mathrm{Xu}$, Downward trend in the prevalence of Helicobacter pylori infectionsand corresponding frequent upper gastrointestinal diseases profile changes in Southeastern China between 2003 and 
2012. Jiang et al. SpringerPlus(2016) 5:1601.

Kist M. Impact of German National Reference Centres on monitoring of antibiotic resistance. Int J Med Microbiol2006; 296(supplement 41): 55e61.

Martínez, L.E., Hardcastle,J.M., Wang,J., Pincus,Z., Tsang, J.,Hoover, T.R., etal.(2016). Helicobacter pylori strains vary cell shape and flagellum number to maintain robust motility in viscous environments. Mol.Microbiol. 99,88-110. doi: $10.1111 / \mathrm{mmi} .13218$

Moleiro, J., Ferreira, S., Lage, P. \& Dias Pereira, A. Gastric malt lymphoma: analysis of a series of consecutive patients over 20 years. United European Gastroenterol. J. 4, 395-402 (2016).

Morgner A, Lehn N, Andersen LP et al. Helicobacter heilmannii-associated primary gastric low grade lymphoma: complete remission after curing the infection. Gastroenterology 2000; 118: $821 \mathrm{e} 828$.

O'Connor, A., Gisbert, J. P., O'Morain, C. \& Ladas, S. Treatment of Helicobacter pylori infection 2015. Helicobacter 20 (Suppl. 1), 54-61 (2015).

Obayo S, Conrad Muzoora, Ponsiano Ocama, Matthew M. Cooney, Tony Wilson, Christopher S. Probert6 Upper gastrointestinal diseases in patients for endoscopy in South-Western Uganda. African H ealth Sciences Vol 15 Issue 3, September 2015; 959- 966.

Oling $\mathrm{M}$, J Odongo, $\mathrm{O}$ Kituuka and $\mathrm{M}$ Galukande Prevalence of Helicobacter pylori in dyspeptic patients at a tertiary hospital in a low resource setting. Oling $e t$ al. BMC Res Notes (2015) 8:256
Ozbek,A.,Ozbek,E.,Dursun,H.,Kalkan,Y.,andD emirci,T.(2010). Can Helicobacter pylori invade human gastric mucosa? An in vivo study using electron microscopy, immunohistochemical methods, and realtime polymerase chain reaction. J.Clin. Gastroenterol. 44,416-422.

Parreira,P., Magalhães,A., Reis,C.A., Borén, T., Leckband,D., and Martins, M. C.(2013). Bioengineered surfaces promote specific protein-glycan mediated binding of the gastric pathogen Helicobacter pylori. ActaBiomater. 9, 8885-8893.

Peek,R.M., and Blaser, M. J. (2002). Helicobacter pylori and gastrointestinal tract adeno carcinomas. Nat.Rev.Cancer $2,28-37$.

Tseng CA, Wang WM \&Wu DC. Comparison of the clinical feasibility of three rapid urease tests in the diagnosis of Helicobacter pylori infection. Dig Dis Sci2005; 50: $449 \mathrm{e} 452$.

Wang F, Sun MY, Shi SL, Lv ZS. Helicobacter pylori infection and normal colorectal mucosa-adenomatous

polypadenocarcinoma sequence: a metaanalysis of 27 case-control studies. Colorectal Dis 2014; 16: 246-252

Warren JR, Marshall BJ (1983) Unidentified curved bacilli on gastric epithelium in active chronic gastritis. Lancet 1:12731275

Yuan, W. et al. Iron deficiency anemia in Helicobacter pylori infection: metaanalysis of randomized controlled trials. Scand. J. Gastroenterol. 45, 665-676 (2010).

\section{How to cite this article:}

Haitham Refaay Mustafa Elshiekh, Amr M. Elrabat, Ahamed M. Sultan and Mahmoud M. Zaky. 2017. Bacteriological Investigation of Helicobacter pylori Infections in Patients with Gastric and Duodenal Ulcer. Int.J.Curr.Microbiol.App.Sci. 6(4): 2753-2765. doi: https://doi.org/10.20546/ijcmas.2017.604.319 